\title{
AGONISTIC BEHAVIOUR OF JUVENILE GULLS, A NEUROETHOLOGICAL STUDY*
}

\author{
By JUAN D. DELIUS \\ Department of Psychology, University of Durham, Durham
}

\begin{abstract}
The results relating to agonistic behaviour obtained during an exploration of the brain of juvenile herring and lesser black-backed gulls (Larus argentatus and fuscus) with electrical stimulation are reported. As an introduction the normal agonistic behaviour of immature gulls is described. While the flight and aggressive behaviour is largely unritualized the threat behaviour is more stereotyped. Three basic threat patterns are distinguished: the arched, hunched, and squat postures. The relationship of these juvenile agonistic patterns with adult courtship is considered. A large number of sites evoking fear behaviour were found, anatomically widely and incoherently distributed. It is demonstrated that the spontaneous fearfulness levels of individual subjects influences the likelihood of obtaining escape eliciting loci. Stimulation of a number of these sites had an after-effect: a persistent, increased probability of escape behaviour. It seems likely that a proportion of the fear sequences elicited were secondary responses to evoked sensory hallucinations and forced small movements. None of the sites explored yielded outright attack behaviour. Thirteen sites yielded characteristic threat sequences. About half of them produced changes in 'mood' persisting for some $15 \mathrm{~min}$. The sites were clustered in a paleostriatal-septal periventricular and an infundibular area. Histological differentiation of the neuroventricular interface at these areas is noted. Based on these it is argued that the secretion of 'liquormones' is responsible for the changes in 'mood' that followed stimulation.
\end{abstract}

While there has been an increasing interest in ever widening circles on the biological bases of agonistic behaviour, knowledge of the physiological processes underlying it are still remarkably deficient. This is true to the extent that this class of behaviour merits no more than a passing reference in current textbooks of physiological psychology (e.g. Thompson 1967; Grossman 1968; Milner 1970). Most of the information available refers almost exclusively to a small number of mammalian species (Garratini \& Sigg 1969; Eleftheriou \& Scott 1971; Moyer 1971). Agonistic behaviour is closely and divergently adapted to the varied socio-ecological environments of different animals and so it seems essential to explore its physiological mechanisms in a wider range of species.

The agonistic behaviour of gulls in their natural environment has been described in considerable detail and the relevant studies have contributed impressively to the factual foundations of comparative ethology (Tinbergen 1953, 1959). They have also provided much of the observational data on which current ethological theorizing about the motivational processes underlying agonistic behaviour is based (Hinde 1970). Gulls thus seemed suitable subjects for investigating the neural correlates of agonistic be-

"Dedicated to the memory of Erich von Holst. haviour in a non-mammalian species. The present paper reports results relevant to this behaviour obtained during a systematic exploration with electrical brain stimulation (Delius 1967, 1971a, 1971b, in preparation) of the forebrain of herring gulls (Larus argentatus) and lesser black backed gulls (L. fuscus), two closely related species of nearly identical behaviour (Goethe 1955a; Brown 1967a). Although the wildness of these animals set limits to the research, some of the results are important in that they suggest the involvement of a special neurohumoral mechanism that has been hitherto neglected in physio-ethological studies.

Since immature animals were used for these experiments and their behaviour has not been described in as much detail as that of adult gulls (Goethe 1955b, 1956), a section summarizing the observations on the agonistic behaviour of normal, unstimulated birds precedes the account of the experimental results.

\section{Methods}

For the electrical brain stimulation experiments I used fifty juvenile herring and lesser blackbacked gulls. They were hatched in an incubator and hand-reared while kept in semi-isolation for 5 weeks; this made them reasonably tame. They then lived in a large aviary in groups of six to 
eight birds and fed on fish, meat and dog biscuits. Water was available in small ponds.

When they were at least 8-months-old, but always before they had reached sexual maturity, they were operated under pentobarbital anaesthesia (Delius 1966a). Up to eight stainless steel electrodes of $0.1 \mathrm{~mm}$ diameter and with 0.25 $\mathrm{mm}^{2}$ uninsulated tips were implanted stereotactically using a modified Stellar-Johnston apparatus (Delius 1966b). In it the gull's head was held by the postorbital spines and by the ridge of the upper mandible close to its base in a standard manner, at an angle that ensured that the brain's anterior-posterior axis was horizontal.

A coarse stereotactic atlas was made based on photographs of unstained thick transversal brain sections. These were prepared by marking the brain of a frozen gull head held in the stereotactic instrument with a stereotactic, horizontal anterior-posterior needle-track and then cutting it with a fine saw at stereotactically specified, transversal planes. Details were filled in from conventional cell and fibre stained serial sections. Brain structures are named according to the Karten \& Hodos (1967) pigeon (Columbia livia) brain atlas.

After a week's recovery the gulls were tested for ten to twenty sessions spread over 2 to 3 months in a $4 \mathrm{~m}^{3}$ case. During each session each electrode was stimulated several times for between $30 \mathrm{~s}$ and $5 \mathrm{~min}$ with $50 \mathrm{~Hz}$ sine wave currents of up to $200 \mu \mathrm{A}$. Control trials without stimulation were interposed regularly.

The birds were killed with an overdose of pentobarbital and perfused with saline and formalin through the carotids. Electrode tips were located in conventionally prepared paraffin sections alternately stained for cells and fibres with cresyl violet and haematoxylin.

Observations of the 'normal' (unstimulated) behaviour of the gulls were made in the home cages of the experimental animals; sometimes the observer was concealed. Eight juveniles in particular were watched intensely for $55 \mathrm{hr}$ spread over 4 months and detailed notes on their behaviour were made. Additional data were obtained by watching from hides at a large breeding colony of herring and lesser blackbacked gulls on Walney Island, Lancashire.

\section{Results}

Normal Behaviour

Herring and lesser black-backed gulls only attain complete sexual maturity and their adult plumage in their fourth year of life, although some individuals become reproductively capable in the third year when they have an intermediate plumage. The agonistic, and for that matter much other behaviour, of first and second year birds differs quite remarkably from that more commonly described, of adult, sexually active birds in the breeding colony. The latter not only show outright fighting, involving pecking, biting, tugging and wing beating. and outright fleeing, either by flight or running, but also a number of ritualized threat postures, actions and vocalizations (Tinbergen 1953; Goethe 1956). Non-breeding adults show a much less obvious and less extreme agonistic behaviour, which is also marked by a relative absence of ritualized threat behaviour.

While still at the breeding colony fledged or nearly fledged first year juveniles show a somewhat intermediate behaviour. Attacks are less violent than in breeding adults and are mainly restricted to reaching-pecks and slow chases. Fleeing during intraspecific encounters consequently consists of a simple side stepping, backing, running or jumping, sometimes accompanied by a screeching call, presumably denoting alarm. In situations likely to release fleeing the birds take up an erect posture with a stretched neck, sleek plumage and wide open eyes; this posture is sometimes accompanied by a small amplitude wing quivering. The beak is held horizontal or pointing slightly upwards. When actually grabbed by an opponent (usually the owner of the territory into which they have intruded), calls are modified into a screaming vocalization that appears to denote pain.

Older juveniles show more energetic attack behaviour which sometimes is quite similar to the supplanting attack of adults. Fleeing is now mostly achieved by flying. Restricted by caging it is replaced by flight intention movements: the wings are held extended in a take-off attitude. A persistent pushing against the wire netting was also a common fear response.

Apart from this unritualized behaviour the juveniles show a graded series of threat postures (Fig. 1). One which has been described frequently and which in certain situations is also shown by adults is a hunched posture, in which the body is held nearly horizontal, the neck is withdrawn and the plumage of the back is ruffled. This posture is given when a conspecific, which might be an adult or juvenile, approaches. It has conventionally been interpreted as a posture expressing subordination and thus indicating 


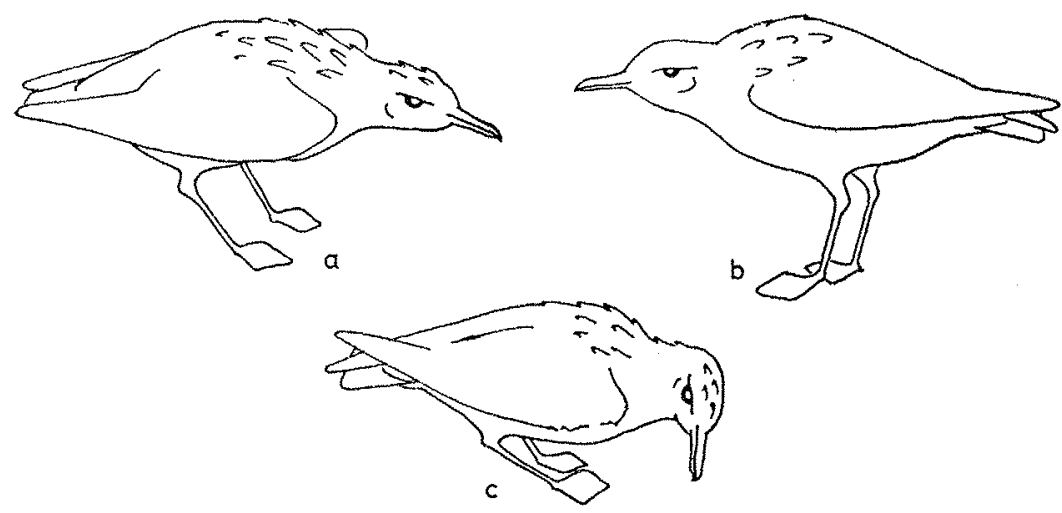

Fig. 1. Some of the threat postures adopted by juvenile herring and lesser black-backed gulls: arched (a), hunched (b), and squat (c). Intermediate postures are frequent.

that fear is predominating. It has also been described as an appeasement posture, i.e. a posture which suppresses aggression in the opponent (Tinbergen 1959). This may well be correct when the opponents are adults or clearly rank superior juveniles, when this behaviour often precedes head tossing, a food begging behaviour. When the opponents are similarly or inferiorly ranking peers however, this posture precedes vicious attacks, as often as it does flight. The position of the head during the hunched posture, held from obliquely upward to obliquely downward, predicts the probability of fleeing or attacking. This is so in the context of several other postures (Tinbergen 1959).

When the juvenile gulls showing the hunched stance neither flee nor attack, the posture is often followed by an apparently irrelevant but quite 'deliberate' squatting with the beak directed downwards. Juveniles which have squatted in this way are likely to resist passively even the most violent attacks by adult conspecifics who, as a rule however, tend to soon lose interest. On occasions the young themselves will lunge into a most vicious attack from this squatting posture (Focke 1968). Observations on two of our experimental birds which were kept until 2 years of age and showed by then some signs of sexual activity, suggested that this behaviour develops into the choking behaviour of adult breeding birds, in that these birds added a repetitive muffled call with nodding movements to the above described behaviour sequence. This immature choking however was only seen on a few occasions.

A variant of this behaviour, already described by Goethe (1963) is one in which the birds adopt a similar posture but with a forward extended arched neck, a fluffed back plumage and often fluffed crown feathers, while approaching the opponent or orienting sidewards to it while walking towards some preferred resting site. Birds which took up this posture were extremely unlikely to flee, and indeed if additionally they held out their carpals and/or even extended their wings, they were quite likely to attack in a very vigorous manner. As described for the hunched posture the arched one is often followed by a deliberate but sometimes incomplete squatting either while facing the opponent or after having arrived at their habitual resting site. Observations on the earlier mentioned 2-year-old animals indicated that this arched stance develops into the so-called arched and mew call sequence of adults; these birds tended to add to the above sequence a drawn-out plaintive call, somewhat similar to the adult mew call and that sometimes developed into an immature long call, a transition that is sometimes also seen in sexually active adults. Adults incidentally also frequently link the arched and mew sequence with a final choking (Brown 1967b) which may explain the tendency of juveniles to squat at the end of the sequence, a behaviour which I have just interpreted as juvenile choking.

It must be mentioned though that the arched and mew call sequence and the choking in adults are no longer solely agonistic behaviours, but they are also, and perhaps mainly, courtship displays, i.e. they function principally as pair. bond sustaining and sexually stimulating be- 
haviour (Brown 1967b). Thus, if our interpretations about the ontogeny of these postures is correct, then there is not only a gradual change in the form of the displays, but also a change in their functions, probably accompanied by modifications of the underlying motivational mechanisms.

A further behaviour sequence clearly denoting fear, which must be in some way related to the ones just mentioned because of the frequent occurrence of intermediates, is one in which birds run rapidly in a semi-crouched posture with sleek plumage and horizontally held head to a hiding place, in the cages to an inaccessible corner, in the wild to a clump of tall vegetation. There they squatted in a frozen attitude which was retained for some time. Interestingly, adults whose wings have been clipped regress to this behaviour in situations where normally they would fly away.

I could not identify any obvious ontogenetic precursors of typical adult agonistic behaviours such as the upright posture and grass pulling, unless some unritualized but similar behaviour shown in non-social situations by the juvenile gulls was such. If this is really so, the ontogeny of these threat postures would involve quite remarkable developmental changes in the afferent causal mechanism initiating them, well worth a study of their own.

\section{Brain Stimulation}

Fear behaviour. Of the 290 brain loci that were explored with electrical stimulation a large number yielded unritualized flight behaviour of some kind. Depending on the precise criteria used for classifying the sites, the number of those that elicited this type of behaviour was between fifty-four and seventy-five. The responses ranged from a fearful, attentive posture involving a stretching of the neck with sleeking of the plumage and wide open eyes to violent and persistent escape behaviour during which the birds attempted to fly away and include fearful behaviour associated with vocalizations that have been already reported elsewhere (Delius 1971a). Quite often, in about 30 per cent of the sites, there was some difficulty in relating the behaviour evoked by stimulation to normal fear behaviour. The loci ranged over a wide spectrum in terms of reliability, variability thresholds and so forth. The interpretation of the information that they yielded is however fraught with difficulties.
Even though an effort was made to raise tame experimental birds the repeated handling that the stimulation experiments necessarily involved tended to arouse their natural fearfulness. Thus in the experimental cage fear behaviour could be elicited by stimuli that normally would not have triggered it. It seems likely that for the same reasons sites that normally would not have yielded fear behaviour did so in these circum. stances. In other words, in these semi-wild birds fear behaviour was excessively facilitated. This is supported by the following findings.

Eleven of the birds were observed in their home cages and classified as either 'tame' or 'fearful' according to their behaviour (in part their response to the presence of the unhidden observer). The seventy-five electrodes with which these birds were implanted were classified according to whether they gave fear/escape behaviour or not. The anatomical locations of the electrode tips were of course not identical for both groups of birds, but their distribution among gross brain regions (telencephalon, pre-optic area, hypothalamus, medial mesencephalon, etc.) was quite similar. Nevertheless stimulation sites in fearful animals were more likely to yield escape/fear behaviour than loci in tame birds $\left(\chi^{2}, P<0.01\right.$, Table $\left.I\right)$.

Table I. Proportion of Fear Eliciting Loci in Tame and Fearful Gulls

\begin{tabular}{lcc}
\hline & $\begin{array}{c}\text { Tame } \\
N=5 \\
34 \text { electrodes }\end{array}$ & $\begin{array}{c}\text { Fearful } \\
N=6 \\
41 \text { electrodes }\end{array}$ \\
\hline $\begin{array}{l}\text { Fear and escape } \\
\text { behaviour }\end{array}$ & 6 & 15 \\
Other behaviour & 28 & 26 \\
\hline
\end{tabular}

The argument that many of the fear responses might have been elicited in an indirect way is supported by the following observations. Stimulation of eighteen sites yielded behaviour sequences that included fear initiated by forced, unnatural, mainly gross movements such as falling over backwards, but sometimes small movements such as an upward flexion of a digit or a torsion movement of an eye, rarely seen in normal birds. These latter small movements could easily be missed by the observer and often were not noticed until ten to fifteen stimulation trials had taken place. The fear/escape behaviour following was seen, once the forced movements had been detected, to be a secondary response 
to them. It was also clear that their intensity depended much on the mood of the animal; if the gull was relaxed when stimulated the digit flexion could occur without any sequel. It is likely that many more of the avoidance responses elicited by brain stimulation may have been due to the activation of such miniature but undetected motor elements with aversive side effects. While most of the sites yielding the sequence of this type that were recognized were located in the brain stem, particularly the mesencephalon, a few were situated in the telencephalon.

Stimulation of another group of electrodes, fifteen to twenty-four, depending on the criteria used, produced a special type of flight behaviour. The animals appeared to avoid, judging by their gaze, either a more or less distant point fixed in space or a point fixed in relation to their body or head. When the point seemed anchored to the surroundings it did nevertheless usually vary in position from one stimulation to another. For example, on one trial a bird would sidle away with a stretched neck while fixating monocularly a point next to its feeding bowl; in the next trial however, it would avoid, in a similar manner, a corner of the cage. There was one regularity that $I$ noticed regarding the orientation of this avoidance: for any given stimulation site the points the gulls locked upon tended to be restricted to a particular height level, i.e. for one site the points always appeared to be located on the floor, while in the case of another site the points fixated were obliquely upwards. Only in the case of three sites did the gulls consistently, for the duration of the stimulation session, orient their avoidance to an actual object in the cage, such as the feeding bowl or a large pebble. If the object was removed they locked on to something else. The behaviour elicited by these electrodes thus agreed with the assumption that the primary response that the stimulation elicited was an aversive, sensory hallucination, much as those reported by human subjects after stimulation of sensory brain structures (e.g. Penfield \& Rasmussen 1950).

Examination of the brain sites yielding the escape and fear behaviour gave, as one might expect from the preceding comments, an extremely confused picture. Classifying the sites according to the behaviour into more unified groups did not help to remove the absolute lack of pattern. I could not discern associations with known major neuronal circuits, nor could I detect any clustering of sites in particular brain areas. However, a proportion of the sites suspected of yielding fear behaviour mediated by hallucinations were indeed located in known mesencephalic, thalamic and telencephalic sensory projections (Boord 1969; Karten 1969; Parker \& Delius 1971; Delius \& Bennetto 1972), but others were not. Similarly not all sites located in sensory areas yielded avoidance or even hallucinatory behaviour. Among the anatomical location data there are several cases where the two electrodes identically placed in two different gulls, one yielded obvious and reliable escape behaviour and the other definitely did not. Generally, points negative with respect to fear and escape behaviour were intermingled with those not eliciting these responses. Even when information on the substrates of fear behaviour in the avian brain given by other authors was used to supplement the gull data, I could not detect meaningful patterns.

Approximately half of the loci yielding fear behaviour showed a post-stimulation after-effect best described as a change in mood (v. Holst \& v. St. Paul 1960): the animals became fearful. The time course of the effect was variable: it might last for $10 \mathrm{~min}$ or persist for an hour, and was mainly expressed in a post-stimulation increase in spontaneous escape behaviour. Figure 2 presents data for three such loci that were studied in some detail. Notice that a very similar effect followed the release of fear behaviour with external stimuli (compare also Delius 1970). A depression of thresholds, a shortening of latencies and an increase of reliability for repeated elicitation of fear behaviour were probable in a number of cases, but the variability of the effects was such that I could not confirm these definitely for any site.

In at least two individuals the repeated stimulation of fear behaviour did probably have a cumulative and nearly permanent effect: tame, relaxed animals became progressively and persistently fearful. Confusing variables such as the concurrent repeated handling do not allow a definite conclusion although in other individuals these factors by themselves were not sufficient to induce such a change in 'personality'.

Aggressive behaviour. Points yielding aggressive behaviour were considerably less common than sites eliciting fear behaviour. None actually yielded anything reminiscent of outright attack. The nearest to such behaviour, excluding attack behaviour as a sequel to threat behaviour 


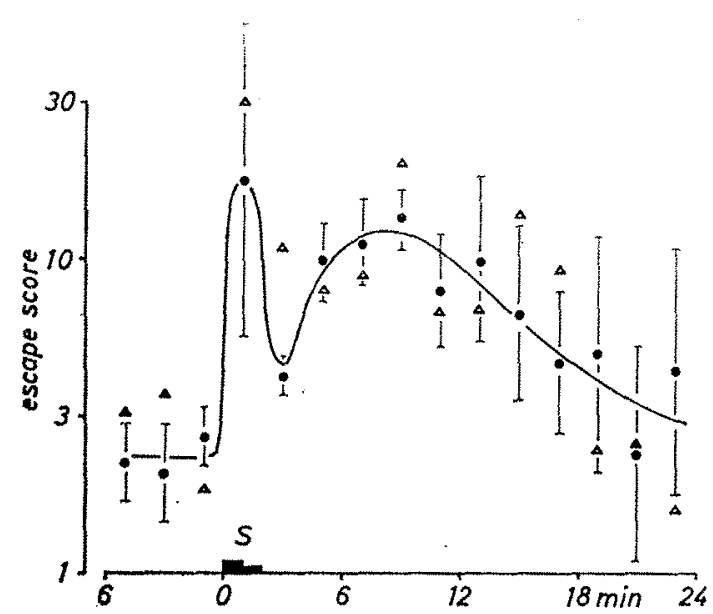

Fig, 2. After-effects following stimulation of three fear behaviour eliciting loci in three gulls. In each twelve trials (four for each bird) the escape attempts of the bird were counted for fifteen consecutive 2 -min periods. On the fourth period (s) a supra-threshold stimulation current was given for 1 or 2 min. The dots are the mean escape scores with SD (both calculated after the log transformation). The triangles are mean escape scores of six trials with two of the birds, where the electrical stimulation was replaced by a 1-min scaring session instituted by the experimenter. No SD are given for these means, but they are considerably larger than those for the stimulation results.

(see below), was elicited from four sites that yielded rather vicious pecking of a type that did not seem to relate to pecking of a foraging or displacement type (Delius 1967, 1971b). The pecks however were not directed at companion animals in the test cage, rather their presence completely suppressed the pecking. In any case the responses could only be elicited with a low reliability factor $(38$ per cent for the most reliable site). For two of these electrodes consistent orienting responses observed before pecking, and even when no pecks were given, suggested that evoked sensory hallucinations may have been the releasers of the hostile behaviour (compare Plotnik, Mir \& Delgado 1971).

More definite results could be obtained for threat behaviour. Striking and complex threat sequences that could be confidently identified with behaviour shown by normal birds (see earlier) were elicited from thirteen out of the 290 sites explored. The loci were comparatively reliable in that a high proportion of trials above threshold yielded the adequate posturing. The average number of positive trials for all thirteen electrodes was 78 per cent $(N=283)$ and the range was between 63 per cent $(N=24)$ and 100 per cent $(N=18)$. Of the eleven birds involved five were males and three females, the other three were not sexed.

The details of the evoked behaviour sequence varied somewhat from locus and also within loci from trial to trial. At one end of the scale the stimulated birds took up a forward bent posture with the neck and head held low and the body held slightly obliquely upwards. The wings were abducted from the body, the crown and the back feathers erected, the posture was accompanied by a rapid running, often with somewhat flexed legs towards a companion bird, a stuffed stoat, the human handler, or just towards a particular spot in the testing cage. The sequence mostly included the delivery of reaching pecks and sometimes actual biting.

An intermediate sequence was one where the wings were held close to the body, the erection of the feathers was mainly restricted to the back and the approach was slower and not directed towards the potential opponent, but rather to a preferred corner of the test cage, where the bird then had a strong tendency to squat in a tense posture. This squatting incidentally is quite different from that which precedes resting and sleeping (Delius 1967). While approaching the squatting place the gull would frequently pick up small pebbles and fling them away sidewards. I never saw this component in nonstimulated threat sequences of juvenile birds, although in play contexts they often handled stones in this way. The behaviour is reminiscent of a low intensity grass pulling, a behaviour that adults show in agonistic encounters. No spontaneous pecking of the opponent occurred but it could be elicited if one held the hand near the gull or else teased it with a stuffed stoat.

At the other extreme of the scale the behaviour elicited consisted of fluffing of the back and lowering of the head, usually with the beak pointing slightly downwards while maintaining a lateral orientation towards a real or imaginary opponent. In this stance the bird would avoid an approaching hand rather than peck at it. However, since the birds did not panic in response to the hand as they often did when not stimulated, they were less fearful than normally.

Except in the case of two of the thirteen sites where co-elicited turning tendencies sometimes interfered, the threat behaviour was well adapted to the immediate circumstances. The animals for example adjusted the orientation and the detailed temporal sequence to the 


\section{P L A T E I I}

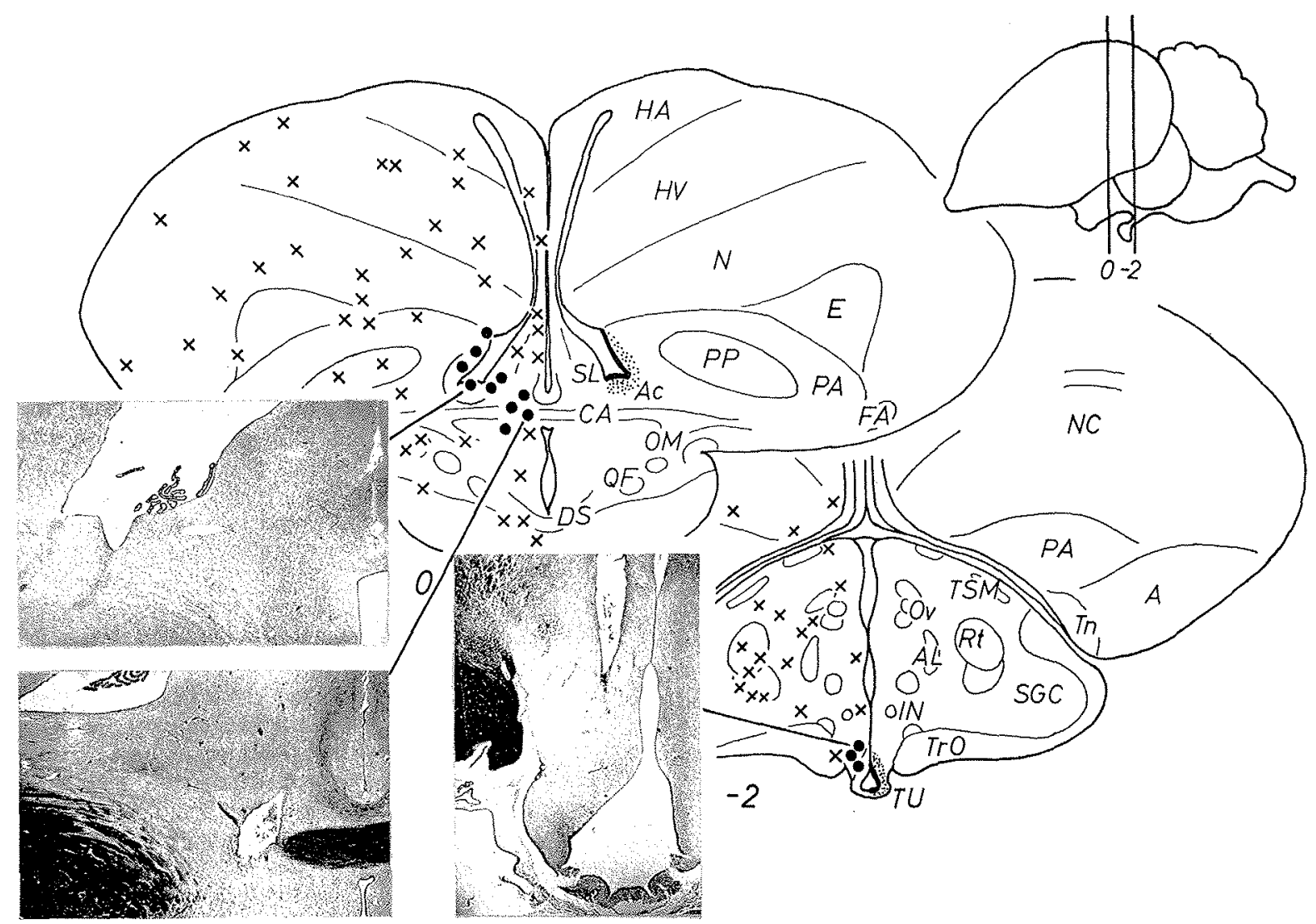

Fig. 4. Location of threat behaviour eliciting electrode tips in herring and lesser black-backed gulls. Dots are positive, crosses negative sites: all sites have been transferred to the left side. The photomicrographs document the location of three typical loci. The thick lined, stippled areas denote the presence of ependymal differentiations (see text). Abbrevations: A archistriatum, Ac nucleus accumbens (see, however, footnote p. 243), AL ansa lenticularis, CA commissura anterior, DS decusatio supraoptica, E ektostriatum, FA tractus fronto-archistriaticus, HA hyperstriatum accessorium, HV hyperstriatum ventrale, IN tractus infundibularis, $\mathrm{N}$ neostriatum, NC neostriatum caudale, $\mathrm{OM}$ tractus occipito-mesencephalicus, OV nucleus ovoidalis, PA paleostriatum augmentatum, PP paleostriatum primitivum, QF, tractus quinto-frontalis, $\mathrm{Rt}$ nucleus rotundus, SGC stratum griseum cellulare, SL nucleus septalis lateralis. Tn nucleus taeniae, TSM tractus septo-mesencephalicus, Tr-O tractus opticus, TU nucleus tuberis. 
movement and actions of the opponent. This, and the fact that the responses elicited clearly varied as a function of the subjects pre-trial behaviour, as well as of the stimulus intensity, largely explains the variability of the behaviour from a given site on different trials.

All sites had, in comparison with other electrodes and responses, medium thresholds ranging between 30 and $70 \mu \mathrm{A}$. The latencies were somewhat variable but mostly they were in the range of 5 to $10 \mathrm{~s}$. All sites showed adaptation in the sense that in order to maintain the response at the similar level of intensity throughout the stimulation train it was necessary to increase the stimulus current in the course of the trial. Typical for this adaptation were instances where during a 1-min stimulation period it was necessary to increase the current from 30 to $50 \mu \mathrm{A}$, or in another case from 60 to $90 \mu \mathrm{A}$.

Six of the thirteen loci elicited a complex but characteristic after-stimulation effect. Firstly the behaviour evoked tended to outlast the stimulation by up to $15 \mathrm{~s}$. Secondly, repeated stimulation revealed a slight and irregular lowering of the threshold current required to reactivate the same behaviour. This threshold depression appeared to last for periods of 5 to $15 \mathrm{~min}$ and would have passed unnoticed except for the fact that it was accomplished by an easily recognizable and persistent change in the behaviour of the birds. They became confident, relaxed, even bold while remaining active. This was particularly noticeable in two normally rather fearful animals. After stimulation they desisted for periods up to $15 \mathrm{~min}$ from escape attempts which they otherwise tended to show while in the testing case (Fig. 3).

In several stimulation sessions there was evidence that this mood after-effect cumulated as stimulation trains were repeated at 3 to $5 \mathrm{~min}$ intervals. They may even have been long-term effects that developed over several stimulation sessions and that lasted perhaps for weeks: one bird that was stimulated for over fifty times with a threat-inducing electrode during a period of 14 days became increasingly aggressive towards companion birds and humans in the home cage and remained so until it was killed some 2 months later (compare Robinson, Alexander \& Browne 1969).

Of the remaining seven sites four almost certainly did not show any comparable aftereffects in spite of responding with well organized behaviour to the stimulation itself. No correlation across electrodes existed between the

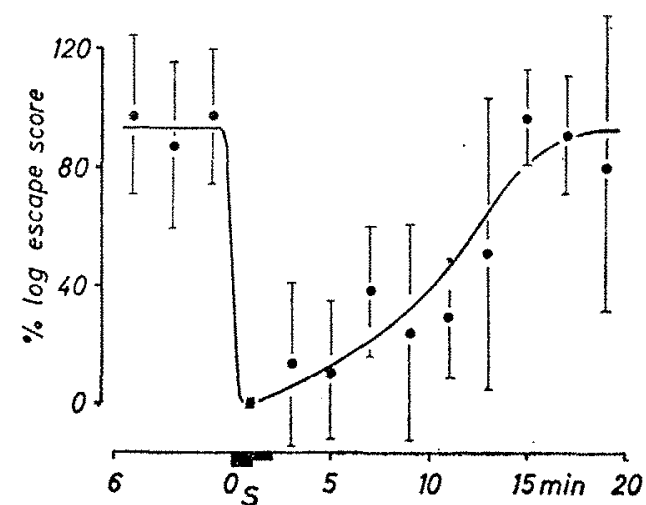

Fig. 3. After-effects following stimulation of two threat behaviour evoking sites in two gulls. The same procedure as described in Fig. 2 was used during eight trials (four with each bird) for thirteen 2-min periods each. Because of considerable differences in pre-stimulation escape score levels the data was converted to percentages of this baseline level.

nature of the overt threat behaviour that they elicited and whether they evoked an after-effect. Even within an electrode the intensity of the overt responses were poor predictors of the magnitude of the after-effects. Since one bird bore an electrode which yielded an after-effect and another electrode which did not, the occurrence of the after-effects is not a characteristic of particular individuals.

The two electrodes that most consistently, but not always, evoked the most aggressive and most striking type of threat sequence, were implanted in birds that were, before stimulation began, naturally among the most aggressive birds in the home cage hierarchy (Goethe 1955b) and that regularly displayed threat postures. Similarly three electrodes that produced the most fearful threat sequences were implanted in two birds that occupied the lowest position in the hierarchy and that were never seen to show threat behaviour when unstimulated. Thus in this respect the individual dispositions did influence the stimulation results.

Contrasting with the diffuse anatomical distribution of fear behaviour loci, the threat evoking electrode tips clustered clearly in two different brain regions (Plate II, Fig. 4). Ten of them were located in an area surrounding the ventral and lateral wall of the lateral ventricles of the forebrain at the level of the anterior commissure, and extending ventralwards, medially and slightly posteriorly of the said commissure. Thus the sites were located within the 
posterior pole of the nucleus accumbens*, within the nucleus septalis lateralis and just within the dorsal edge of the nucleus periventricularis medialis. The remaining three electrodes were located in the nucleus tuberis (=infundibularis= arcuatus: Oehmke 1968) in the ventral hypothalamus. In the discussion I will draw attention to certain further pecularities of these locations.

Attempts at relating characteristics of electrodes such as threshold currents, latencies, reliability, precise behaviour, after-effects, with their location did not reveal anything clear-cut.

\section{Discussion}

Compared with similar studies on other species (Akerman 1966a, b: pigeon; Putkonen 1967: chicken Gallus domesticus; Maley 1969: mallard Anas platyrhynches) a very high proportion of the brain sites explored with electrical stimulation in gulls evoked escape behaviour. This was probably due to the fact that fear was an already highly likely type of responding in most of the experimental birds. In the same way that insignificant external stimuli elicited their escape behaviour the stimulation of probably minor neural events were also capable of provoking fear. That natural fearfulness of the subjects increased the probability of finding escape eliciting loci was established. Effectively fearful animals appear to have a more widely distributed neural fear system than tame ones. Does this merely reflect dynamic differences, say in terms of synaptic activity, or does it involve structural differences, say in terms of synaptic connectivity? Based on admittedly circumstantial and involved evidence I am inclined to think that structural differences must be seriously considered (see also Valenstein 1969). However this may be, from a heuristic point of view it is obvious that more useful information about the essential components of the neural system underlying fear will be obtained from stimulating selected, uniformly non-fearful individuals. That the behavioural response propensities of individuals are a confusing factor when assessing the functional contribution of neural structures has been often pointed out (Doty 1969).

The localization of structures subserving threat behaviour in the gulls does not suffer from similar constraints. It was elicited on a background of behavioural tendencies that was, if anything, biased against it. The clustering of effective sites in two brain areas may therefore

*It now seems likely that the area in question is equivalent to the nucleus stria terminalis of Zeier \& Karten (1971). be taken as indicating the presence there of fundamental neuronal components of the network underlying this behaviour.

Comparison of anatomical substrates of threat behaviour that other authors have published for other bird species (Akerman 1966a, b; Putkonen 1967; Harwood \& Vowles 1967; ring dove Streptopelia risoria; Maley 1969) with that of juvenile herring and lesser black-backed gulls supported this view. Even though there are some difficulties in equating behaviour across species it is clear that generally these authors give a much wider anatomical distribution of positive stimulation points than $I$ found in gulls. This could be so because of the reasons just aduced and also because I was using immature animals that lacked the hormonal facilitation that undoubtedly is essential for much of the aggressive-defensive behaviour of birds (see Boss 1943).

Nevertheless Akerman (1966a, b), Harwood \& Vowles (1967), Putkonen (1967) and Cannon \& Salzen (1971: domestic chick) report eliciting comparable behaviour from sites coinciding with the septal-paleostriatal cluster of the gulls. Putkonen's data is interesting because he specifically elicited a 'fear and threat crouching' from this area. Forman \& Allee's (1959) description of this behaviour of chickens makes it appear surprisingly similar to the syndrome that the gulls showed. Cannon \& Salzen's loci yielding a probably comparable 'hiding' with flight and aggressive pecking, were located quite precisely in the same area as the threat evoking sites in the gulls. Akerman reports having obtained courtship-threat sequences from the area in question in pigeons. This might relate to the additional sexual function that I suspect the threat behaviour of juveniles acquires in adult gulls. Brown (1971: redwinged blackbird, Agelaius phoniceus) interestingly reports eliciting vocalizations from approximately the same region but his subjects could not behave freely and thus we do not know whether the calls would have been accompanied by threat behaviour. Maley (1969) did not stimulate in the relevant brain area and none of the quoted authors explored infundibular sites. Phillips \& Youngren (1971) have recently published sites evoking threat and crouching behaviour in chickens that agree with the foregoing observations.

The threat behaviour I obtained does not accommodate well with current ethological theorizing on the organization of agonistic be- 
haviour. The hypothesis is that agonistic behaviour can be understood as resulting from two independently arousable behaviour tendencies, to attack and to flee, and interactions between the two. This latter process, termed confict, is thought to be responsible for the release of threat behaviour. The nature of the tendencies and the interactions is not stated in any explicit detail. Sometimes it is specifically claimed that the hypothesis makes no pretence of relating to physiological mechanisms but it is difficult to see how a hypothesis intended to explain the short term causation of a behaviour can ignore them. It is true though that the hypothesis was originally conceived, necessarily so at the time, without regard to physiological information (Blurton-Jones 1968; Hinde 1970). As such information has become available (e.g. Brown \& Hunsperger 1963) it has proved difficult to fit in.

Notice that I was able to elicit well-developed threat and fear behaviour without ever evoking any outright attack behaviour. What attack behaviour was observed developed from preceding threat behaviour. It might be argued that the fact that I always obtained threat behaviour may have been due to having stimulated an actual attack tendency but which, because it conflicted with the natural fearfulness of the experimental birds resulted in threat. Against this I present evidence that external stimuli normally inducing fear when superimposed on an evoked threat tended to enhance attack behaviour. This rather suggests that attack behaviour may be a result of a conflict between threat and fear tendencies, a conception that is reminiscent of the vernacular statement that 'only cornered animals attack'. A motivational mechanism of this type makes some functional sense and it probably would not be difficult to make a fact-based case for its existence.

Attempts to attack this problem more directly by simultaneously stimulating a threat eliciting and a fear evoking site (this was possible in three birds) were unsatisfactory because invariably one of the responses suppressed the other. Current adjustments only lead to an alternation of the suppressing behaviour (see also von Holst \& von St Paul 1960; Brown, Hunsperger \& Rosvold 1969). Nevertheless, sometimes when the stimulation eliciting a suppressing fear response was switched off while still stimulating the threat eliciting locus a brief rebound intensification of this latter behaviour occurred. Mostly this involved a flurry of forceful pecks against a companion bird.

However this may be, the explanatory value of these types of hypotheses must now be regarded as restricted. Much more detail about the causal structure of the tendencies and their interactions is needed to make them capable of stimulating empirical research. Whether this can be done without introducing an intractable degree of complexity is another matter. In view of the fact that agonistic behaviour, even in a single species, has multiple functions, complexity may indeed be a realistic characteristic to assume for a system that has to optimize all of them.

I now turn to the after-effects that follow stimulation of some of the fear and threat eliciting sites. Although the results relating to threshold changes were not as clear cut as those obtained by Harwood \& Vowles (1967) in the ring dove, there can be little doubt that the poststimulatory changes in mood I describe are related to the phenomenon that they so admirably studied. The time course of events in my data corresponds rather closely with those that they describe and some of the loci they found to yield after-effects were located in the same area as some of mine.

After-effects with time constants of the order of 5 to $30 \mathrm{~min}$ are frequently encountered in ethological studies (e.g. Delius 1969; Heiligenberg \& Kramer 1972). There is however a relative lack of known physiological mechanisms that have time constants of similar order: neural phenomena, at least those that are reasonably understood, have too short, hormonal phenomena too long constants (Horn \& Hinde 1970; Komisaruk 1971). I believe that certain histological particularities regarding the brain areas from where I obtained threat behaviour may be indicating a mechanism that could have adequate temporal characteristics.

Examination of the histological sections containing electrode sites located closest to the ventral edge of the lateral telencephalic ventricles revealed that in this region specifically the ependyma that lines the ventricles' ventral and lateral walls is thickened and that the neural tissue just behind it stains strikingly darker than the surrounding tissue. Comparable sections, but which bore no electrode sites showed that this was not a pathological modification due to the presence of the electrode tips. In better quality cresyl violet stained sections of pigeon brains the differentiation in question is more apparent. It coincides with the posterior 
pole of the nucleus accumbens of the Karten \& Hodos (1967) atlas (see, however, footnote p. 243), although in a less differentiated way it may extend anteriorly for the whole length of the nucleus. Greater magnification suggests that neurons of this nucleus make contact with the ventricular cavity through axon- or dendriteprotrusions, The multilayered ependyma often appears to be covered with a secretory slime. A sizeable blood vessel courses through the posterior end of this area, and the most rostral convolutions of the anterior choroid plexus are just level with it. Notice that not all the effective pre-optic electrodes are in the immediate vicinity of this ependymal differentiation. Fibre stained material however reveals a sufficient number of fibres that course through the septal area in such a direction that they allow the tentative assumption that these other electrodes may have operated by activating fibres ortho- or antidromically afferent to the ventricular structure.

Liquor contacting neurons, sometimes clustered in specialized organs, have recently been found to have widespread distribution in the vertebrate ventricular system (Sterba 1969; Vigh et al. 1971). Their function could be both secretory and receptive. Specialized ependymal organs that have doubtlessly secretory function have been known for some time (Sterba 1969). The particular differentiation in the telencephalic ventricles that I refer to, does not seem to have been previously described. Indeed, inspection of ventricular walls of the avian telencephalon suggests that many more differentiated neuroliquor interfaces than have yet been described may exist.

Turning now to the electrodes located in the tuberal region we again find these to be in the close neighbourhood of such a specialized structure. The general appearance of the ventricular wall of the nucleus tuberis is similar to that of the telencephalic differentiation described earlier. In chickens the presence of liquorcontacting neurons in this nucleus has already been established electron-microscopically (VighTeichman, Vigh \& Aros 1971).

I thus speculate that stimulation of at least some of the neural structures that lead to threat behaviour in juvenile gulls colaterally initiate secretion of an unknown substance into the ventricles that in turn can be detected by receptor elements located in the neuroliquor interface and hence modify the excitatory state of neural systems responsible for the same and other behaviours. The effect persists until the 'liquormones' have been inactivated, perhaps by the choroid plexi. This may well be a general mechanism operating in the control of behavioural moods, and indeed direct supportive evidence for the existence of such processes is already extant from cerebrospinal fluid transfusion experiments (e.g. Myers 1968; Fencl, Koske \& Pappenheimer 1971). The infundibular loci are of course a tempting excuse for speculations about the relationship between these ventricular mechanisms and conventional hormonal processes (compare Oksche \& Oehmke 1971; Rodriguez 1970). These latter might in turn be responsible for the cumulative and more persistent after-effects that seemed to occur in response to repeated stimulation (see Harwood \& Vowles 1967).

\section{Acknowledgments}

The research was supported by grants to Professor N. Tinbergen, F.R.S., and the author from the Science Research Council, the United States Air Force and the Royal Society. It was largely done at the Department of Zoology, Oxford. The assistance of Dr R. G. B. Brown, Mrs J. McFarland, Dr G. Thompson, Mr. S. Graham, Dr J. Chou, and Mr A. Jackson is gratefully acknowledged.

\section{R E F E R E N C E S}

Akerman, B. (1966a). Behavioural effects of electrical stimulation in the forebrain of the pigeon. $\mathrm{Re}-$ productive behaviour. Behaviour, 26, 323-338.

Akerman, B. (1966b). Behavioural effects of electrical stimulation in the forebrain of the pigeon. Protective behaviour. Behaviour, 26, 339-350.

Blurton Jones, N. G. (1968). Observations and experiments on causation of threat displays of the great tit. Anim. Behav. Monogr., 1, 75-158.

Boord, R. L. (1969). The anatomy of the avian auditory system. Ann. N.Y. Acad. Sci., 167, 186-198.

Boss, W. R. (1943). Hormonal determination of adult characters and sexual behaviour in herring gulls. J. exp. Zool., 94, 181-203.

Brown, J. L. (1971). The exploratory study of vocalization areas in the brain of the redwinged blackbird. Behaviour, 39, 91-127.

Brown, J. L. \& Hunsperger, R. W. (1963). Neuroethology and the motivation of agonistic behaviour. Anim. Behav., 11, 439-448.

Brown, J. L. \& Hunsperger, R. W. \& Rosvold, H. E. (1969). Interaction of defense and fight reactions produced by simultaneous stimulation of two points of the hypothalamus of the cat. Exp. Brain Res., 8, 130-149.

Brown, R. G. B. (1967a). Species isolation between the herring gull and lesser black-backed gull. Ibis, 109, 310-318.

Brown, R. G. B. (1967b). Courtship behaviour in the lesser black-backed gull. Behaviour, 29, 122-153.

Cannon, R. E. \& Salzen, E. A. (1971). Brain stimulation in newly-hatched chicks. Anim. Behav., 19, 375-385 
Delius, J. D. (1966a). Pentobarbital anaesthesia in the herring and lesser black-backed gull. J. small anim. Pract., 7, 605-609.

Delius, J. D. (1966b). Some techniques for the electrical brain stimulation of small unrestrained animals. Med. biol. Engng, 4, 393-397.

Delius, J. D. (1967). Displacement activities and arousal. Nature, Lond., 214, 1259-1260.

Delius, J. D. (1969). A stochastic analysis of the maintenance behaviour of skylarks. Behaviour, 33, 137-178.

Delius, J. D. (1970). The effect of daytime, tides and other factors on some activities of lesser blackbacked gulls. Rev. Comp. Anim., 4, 3-11.

Delius, J. D. (1971a). Neural substrates of vocalization in gulls and pigeons. Exp. Brain Res., 12, 64-80.

Delius, J. D. (1971b). Foraging behaviour patterns of herring gulls elicited by electrical forebrain stimulation. Experientia, 27, 1287-1289.

Delius, J. D. \& Bennetto, K. (1972). Cutaneous sensory projections to the avian forebrain. Brain Res., $37,205-221$.

Doty, R. W. (1969). Electrical stimulation of the brain in a behavioural context. Ann. Rev. Psychol., 20, 289-320.

Eleftheriou, B. E. \& Scott, J. P. (1971). The Physiology of Aggression and Defeat. New York: Plenum.

Fencl, V., Koske, G. \& Pappenheimer, J. R. (1971). Cerebrospinal fluid from goats that affect sleep and activity in rats. J. Physiol. (Lond.), 216, 565-589.

Focke, E. (1968). Zum Verhalten junger Silbermöwen bei Bedrohung durch adulte Artgenossen. Vogelwarte, 24, 262-266.

Forman, D. \& Allee, W. C. (1959). A correlation between posture stance and outcome in paired contests of domestic hens. Anim. Behav., 7, 182-188,

Garratini, S. \& Sigg, E. B. (eds.) (1969). Aggressive Behaviour. Amsterdam: Excerpta Medica.

Goethe, F. (1955a). Vergleichende Beobachtungen zum Verhalten der Silbermöwe und der Heringsmöwe. Acta XI Congr. Int. Orn., 1954, 577-582.

Goethe, F. (1955b). Beobachtungen bei der Aufzucht junger Silbermöwen. $Z$. Tierpsychol, 12, 402-433.

Goethe, F. (1956). Die Silbermöwe. Wittenberg: Ziemsen.

Goethe, F. (1963). Verhaltensunterschiede zwischen europäischen Formen der Silbermöwengruppe. J. Ornithol., 104, 129-141.

Grossman, S. P. (1968). A Textbook of Physiological Psychology. New York: Wiley.

Harwood, D. \& Vowles, D. M. (1967). Defensive behaviour and the after effects of brain stimulation in the ring dove. Neuropsychologia, 5, 345-366.

Heiligenberg, W. \& Kramer, V. (1972). Aggressiveness as a function of external stimulation. J. comp. Physiol., 77, 332-340.

Hinde, R. A. (1970). Animal Behaviour. London: McGraw Hill.

Horn, G. \& Hinde, R. A. (eds.) (1970). Short-Term Changes in Neural Activity and Behaviour. London: Cambridge University Press.

Karten, H. J. (1969). The organization of the avian telencephalon and some speculations on the phylogeny of the amniote telencephalon. Ann. N.Y. Acad. Sci., 167, 164-179.

Karten, H. J. \& Hodos, W. (1967). A Stereotaxic Atlas of the Brain of the Pigeon (Columbia livia). Baltimore: Johns Hopkins.

Komisaruk, B. R. (1971). Strategies in neuroendocrine neurophysiology. Am. Zool., 11, 741-754.
Maley, M. J. (1969). Electrical stimulation of agonistic behaviour in the mallard. Behaviour, 34, 138-160.

Milner, P. M. (1970). Physiological Psychology. London: Holt, Rinehart \& Winston.

Moyer, K. E. (1971). The Physiology of Hostility. New York: University of Chicago Press.

Myers, R. D. (1968). Transfusion of cerebrospinal fluid and tissue bound chemical factors between the brains of conscious monkeys. Physiol. Behav., $2,373-377$.

Oehmke, H. J. (1968). Regionale Strukturunterschiede im Nucleus infundibularis der Vögel. Z. Zellforsch., 92, 406-421.

Oksche, A. \& Oehmke, H. J. (1971). Weitere Aspekte der Lokalisation, Ultrastruktur und Funktion der Sexualzentren des Hypothalamus. $J$. Neuro. Visc. Relations Suppl. 10, 15-21.

Parker, D. M. \& Delius, J. D. (1971). Visual evoked potentials in the forebrain of the pigeon. Exp. Brain Res., 14, 198-209.

Penfield, W. \& Rasmussen, A. T. (1950). The Cerebral Cortex in Man. New York: Macmillan.

Phillips, R. E. \& Youngren, O. M. (1971). Brain stimulation and species-typical behaviour: activities evoked by electrical stimulation of the brains of chickens. Anim. Behav., 19, 757-779.

Plotnik, R., Mir, D. \& Delgado, J. M. R. (1971). Aggression, noxiousness and brain stimulation in unrestrained rhesus monkeys. In: The Physiology of Aggression and Defeat (Ed. by B. E. Eleftheriou and $\mathbf{J}$. Scott). New York: Plenum.

Putkonen, P. T. S. (1967). Electrical stimulation of the avian brain. Ann. Acad. Sci. Fenn. A, 130, 1-95.

Robinson, B. W., Alexander, M. \& Browne, G. (1969). Dominance reversal resulting from aggressiveness responses evoked by brain telestimulation. Physiol. Behav., 4, 749-752.

Rodriguez, E. M. (1970). Morphological and functional relationships between hypothalamo-neurohypophysial system and cerebrospinal fluid. In: Aspects of Neuroendocrinology (Ed. by W. Bargmann and B. Scharrer). Berlin: Springer.

Sterba, G. (ed.) (1969). Zirkumventrikuläre Organe und Liquor. Jena: VEB Fischer.

Thompson, R. F. (1967). Foundations of Physiological Psychology. New York: Harper.

Tinbergen, N. (1953). The Herring Gull's World. London: Collins.

Tinbergen, N. (1959). Comparative studies of the behaviour of gulls: a progress report. Behaviour, $15,1-70$.

Valenstein, E, S. (1969). Behaviour elicited by hypothalamic stimulation. Brain Behav. Evol., 2, 295-316.

Vigh, B. Vigh-Teichman, I., Koritsansky, S. \& Aros, B. (1971). Ultrastructure of the spinal CSF contacting neuronal system in the white leghorn chicken. Acta Morphol. Acad. Sci. Hung., 19, 9-24.

Vigh-Teichman, I., Vigh, B. \& Aros, B. (1971). Liquorkontaktneurone in Nucleus infundibularis des Kükens. Z. Zellforsch., 112, 188-200.

von Holst, E. \& von St Paul, U. (1960). Vom Wirkungsgefüge der Triebe. Naturwissenschaften, 47, $409-422$.

Zeier, H. \& Karten, J. (1971). The archistriatum of the pigeon: organization of afferent and efferent connections. Brain Res., 31, 313-326.

(Received 31 May 1972; revised 10 August 1972; MS. number: 1144) 